\title{
Etnografía asociada al pavo doméstico en el entorno de Perín (Cartagena)
}

\section{The Ethnography associated with the Domestic Turkey in Perín (Cartagena)}

\author{
Juan ORTEGA MADRID \\ Licenciado en Veterinaria e investigador etnográfico *
}

\begin{abstract}
Resumen: El trabajo muestra un estudio descriptivo sobre diferentes aspectos etnográficos relacionados con el pavo doméstico (Meleagris gallopavo) en el entorno de la diputación cartagenera de Perín. Comienza con un apartado de avicultura tradicional donde se muestran aspectos sobre manejo, reproducción, alimentación, alojamiento, etnoveterinaria, cría y engorde. Se prosigue describiendo la forma típica de matanza y de consumo de sus carnes. A continuación, se realiza un repaso sobre costumbres, juegos, cuentos de tradición oral y fraseología. Igualmente se muestran los abundantes paralelos etnográficos, existentes en la misma zona, con el ganado porcino.
\end{abstract}

Palabras clave: Pavo; avicultura tradicional; matanza; cuento; fraseología.

\begin{abstract}
The work shows a descriptive study on different ethnographic aspects related to the domestic turkey (Meleagris gallopavo) in the area of Perín (Cartagena). It begins with a section of traditional poultry farming where aspects on management, reproduction, feeding, lodging, ethnoveterinary, breeding and fattening are shown. It continues describing the typical way of slaughter and consumption of their meats. Next, a review of customs, games, folk tales and phraseology is made. Also abundant ethnographic parallels with pigs in the same area are shown.
\end{abstract}

Key words: Turkey; Traditional Poultry Farming; Slaughter; Folk Tales; Phraseology.

\footnotetext{
* Recibido: 10, enero, 2018. Aceptado: 15, mayo, 2018.
}

Email: perineros@yahoo.es. 


\section{INTRODUCCIÓN}

El pavo es una gallinácea foránea que se introdujo en España tras el descubrimiento del Nuevo Mundo, procedente del Imperio Azteca. Desde entonces pasó a formar parte habitual de la avifauna doméstica de las zonas rurales. No obstante, parece que su consumo entre la clase trabajadora no se generalizó hasta entrado el siglo XX, siendo hasta entonces un bocado exclusivo de nobles y burgueses. ${ }^{1}$ Tras su llegada a Europa en el siglo XVI se le llamó durante largo tiempo pollo o gallina de la India, debido a que al continente americano se le conocía como la India occidental. ${ }^{2}$ Posteriormente, sus semejanzas físicas y comportamentales con su pariente oriental, el pavo real (Pavo cristatus), le dieron su definitivo nombre, pavo, del latín pavus (pavo real).

Perín es un enclave rural situado en la zona oeste del municipio de Cartagena (Murcia). Tradicionalmente fue una zona desfavorecida, caracterizada por una economía básicamente agropastoril y de autoabastecimiento. Esto sumado a un entorno geográfico agreste, montuoso y mal comunicado con la urbe, propició que las familias tuvieran que ser en gran medida autosuficientes. ${ }^{3}$ Por ello, la venta del pavo suponía un ingreso adicional a las míseras rentas de los hogares y su carne era parte destacada de la tríada de alimentos estrella de la Navidad de antaño. ${ }^{4}$

\section{CICLO PRODUCTIVO DEL PAVO}

En este apartado, que bien podríamos denominar de meleagricultura tradicional, veremos el conjunto de técnicas y de conocimientos populares relativos a la cría del pavo.

1 SÁNCHEZ CONESA, J.: «La gastronomía navideña», La Verdad, 18 de diciembre de 2013, p. 6.

2 LARBALÉTRIER, A. y VERMONT, A.: Los animales de corral, París: Garnier Hermanos, ca. 1900, p. 273.

3 Para ampliar información sobre la idiosincrasia de la zona de estudio y del colectivo humano que la habitaba cfr. ORTEGA MADRID, Juan: «Pocilgas tradicionales en la diputación de Perín», $I V$ Congreso Nacional de Etnografia del Campo de Cartagena, Cartagena, UPCT, 2015, pp. 97-9.

4 Hasta no hace muchas décadas la carne y las chacinas del cerdo (cuya matanza acontecía en época prenavideña), la carne de pavo (que como veremos se sacrificaba en vísperas de Nochebuena), pollo o gallina, y el confite navideño (fundamentalmente representado por rollos de creciente, mantecados y cordiales) eran los tres pilares que sustentaban las comidas de Pascua. Cfr. ORTEGA MADRID, Juan: «Etnografía asociada al porcino en el entorno de Perín (Cartagena)», Revista Murciana de Antropología, 24, 2017, pp. 264-7. Sobre el confite navideño y por tener la figura del animal aquí tratado citaré, a modo de curiosidad, las localmente famosas pavicas de mazapán. Porciones de mazapán con forma de pavo vendidas antaño, por las fiestas de los pueblos, por el conocido como tío Cirilo. 


\subsection{Variedades tradicionales}

Antes de nada, señalar que las variedades tradicionales eran la de fenotipo negro y la pintada, conocida esta última como pavos sarabios $^{5}$ (plumas negras con pintas blancas).

Por tanto, los pavos blancos o de otras tipologías cromáticas, son razas o híbridos introducidos en las últimas décadas debido a que sus canales alcanzan pesos considerablemente mayores. ${ }^{6}$

\subsection{Reproducción y cría}

Los animales se adquirían pequeños, comprándolos con pocas semanas de vida a algún lugareño que tuviera una pollada de pavos o, por el contrario, se criaban en casa. En este caso, ${ }^{7}$ si no se disponía de una pareja de pavos reproductores, se conseguían algunos huevos de algún vecino que sí tuviera y se incubaban

5 Para la voz zaradío, SÁNCHEZ VERDÚ, A. y MARTÍNEZ TORRES, F.: Diccionario popular de nuestra tierra, Murcia: La Opinión, 1999, p. 610, recoge en Moratalla la acepción de grisáceo. En la misma línea GÓMEZ ORTÍN, F.: Vocabulario del noroeste murciano, Murcia: Editora regional de Murcia, 1991, p. 431, señala igualmente a Moratalla, indicando que hace referencia a un gallo o gallina de plumaje gris ceniciento con pintas blancas y negras. Puede que nuestro vernáculo sarabio, no recogido en ninguno de los diccionarios dialectales murcianos, proceda del adjetivo zaradío, fruto del seseo y de la sustitución de la /d/ por una /b/ por un fenómeno de equivalencia acústica. No obstante, teniendo en cuenta que el plumaje de estos animales no era gris, sino de fondo negro salpicado en blanco, es posible que sean vocablos no relacionados. Señalar que sarabia, en gallego, es granizo, y que, en Méjico, lugar de origen del pavo, existe una población con el mismo nombre. Por tanto, un pavo sarabio bien podría ser un pavo negro con motas blancas que recuerden los blancos granos del granizo o, por el contrario, que haga referencia a la procedencia primigenia de los primeros ejemplares que llegaran a la península (recordar que a los primeros pavos que llegaron a Europa se les llamó gallinas de Indias). Como curiosidad, señalar que LARBALÉTRIER, A. y VERMONT, A. (ca. 1900, p. 275) describían, hace ya más de una centuria, la existencia de cuatro variedades de pavos en función del color de su plumaje: negro, blanco, rojo y jaspeado. A este último lo define como de plumaje negro con matices blancos, lo que cuadra con nuestro vernáculo sarabío.

6 Me contaban que los machos de la variedad blanca alcanzan pesos que rondan los $20 \mathrm{~kg}$, afirmando que sus «muslos parecen los de un cabrito».

7 Generalmente una variedad conocida como mericanas (o americanas), raza de gallina de pequeño porte con unas excepcionales cualidades maternales. Me contaban que «las pavas son más tontas, las mericanas son más listas»: rápidamente enseñaban a su prole (adoptiva) a buscar la comida y los defendían de los ataques del temido gavilán. Circulan diferentes anécdotas donde la mericana frustraba las intentonas predatorias de la rapaz realizando alardes de fuerza y valentía con sorprendentes saltos y vuelos. Interesante razonamiento es el aportado por VAN TRICHT, P. Víctor: Nuestros animales domésticos (IV las aves del corral), Bilbao: Imprenta del Corazón de Jesús, 1902, p. 34-5, donde indica que la producción de huevos está inversamente relacionada con la capacidad de incubación, concluyendo que las grandes ponedoras no empollan. Esto explicaría el porqué la gallina americana, variedad poco ponedora, es una excelente incubadora. 
con gallinas cluecas que actuaban de nodrizas. Cuando sí se tenían, algo poco habitual ya que la mayoría de las familias solamente engordaban unos pocos ejemplares, pero no reproducían, había que tomar ciertas medidas para con la madre. Esto es porque durante la incubación, que dura entre 28 y 30 días, decían que era frecuente que la pava no saliera del nido y, por ende, no comiera, por lo que «se le ponía el tiesto con agua y con comida allí al lao» o incluso había que alimentarla de manera forzada. Me contaban que «había algunas pavas muy tontas que no comían y se les daba pan y vino pa que se pusieran en calor». Esto se hacía con un preparado reconstituyente elaborado con un amasijo de ajos picados, pimienta en grano, pan mojado en vino, y garbanzos remojados y machacados. A continuación, se abría el pico del animal y se le embuchaba para «que se pusiera fuerte y entrara en calor». Con el mismo objetivo, tras el nacimiento de los pavipollos o pavicos, era costumbre obligarlos a ingerir un grano de pimienta o «garbanzos remojaos y masticaos por la boca de uno» para que cogieran fuerza y vitalidad. ${ }^{8}$

Si únicamente se poseía la pava de cría (no se tenía macho), era costumbre realizar la práctica del «cabo padre». Esto consistía en llevar la hembra al corral de un macho, propiedad de algún vecino, durante unas horas y cada varios días con el objetivo de que se produjera la cubrición o pisado. Como compensación, el propietario del macho recibía uno de los pavipollos que nacieran de esa nidada.

La pava hace una sola postura (en ocasiones dos) en primavera de hasta $15 \mathrm{o}$ 16 huevos. Los pollos de pavo nacen cubiertos de plumón y, al igual que el resto de gallináceas, tienen un comportamiento nidífugo. Esto significa que, prácticamente nada más nacer, y siempre bajo los atentos cuidados de la madre, son capaces de desplazarse en busca de alimento y de refugio, siendo en esas primeras semanas especialmente susceptibles a sufrir hipotermia.

8 Similares prácticas han sido documentadas por CARMONA MARTOS, J. M.: Almería tierra de cortijos, $2^{\text {a }}$ ed. Almería: Autor, 2015, pp. 295-6 y 339; y RABAL SAURA, G.: El saber botánico popular en el municipio de Cartagena, Cartagena: UPCT, 2014, p. 206. Los ingenieros agrónomos LARBALÉTRIER, A. y VERMONT, A. (ca. 1900, p. 280) confirman en su tratado el citado comportamiento de la pava y las mencionadas prácticas de manejo por parte de sus cuidadores. Así, indican que hay que «obligarlas a que dejen el nido una vez al día para que coman [...] Esta comida no deberá durar más de quince minutos [...] Es tan imperiosa en las pavas la necesidad de empollar, y lo hacen con tanto ardor, que por no abandonar sus crías (huevos), morirían de inanición». De hecho, tales son las cualidades para la incubación, que dichos autores incluso señalan el uso de pavas cluecas para empollar huevos de gallina. Respecto al uso de vino como reconstituyente, lo citan hasta en cinco ocasiones, pero no solo destinado a las pavas como se hacía en la zona de estudio, sino también en los animales de engorde (Ibídem, pp. 279, 281, 289 y 290). 


\subsection{Alimentación y engorde}

El pavo es un animal omnívoro, que se alimentaba a base de granos de cereales (cebada fundamentalmente, porque era el principal cultivo de la zona, y maíz) y de leguminosas, ${ }^{9}$ amasijos de harina de cebada o de harinilla, ${ }^{10}$ hierbas, ${ }^{11}$ higos (frescos o secos y partidos) e invertebrados. Éstos eran los llamados cucos y bichos, totum revolutum donde se incluyen, entre otros, lombrices de tierra, orugas, grillos, cochinillas (marranicas) o saltamontes. ${ }^{12}$ Mención especial requieren estos últimos, los saltamontes, insecto conocido localmente por los vernáculos de langostín o saragustín, y por el que al parecer sentían una gran apetencia los pavos. Cuentan que «estaban por los bancales y les levantabas una piedra y acudían a comerse los bichicos».

9 Garbanzos y habas remojadas. Los garbanzos, como ya se ha indicado, se usaban para fortalecer a los recién nacidos y a las pavas cluecas; mientras que las habas se les daban a los animales de engorde en las semanas previas a la Navidad.

10 La harinilla es un subproducto de molinería usado en alimentación animal. Tanto la harinilla como la harina de cebada eran muy apetecidos por los diferentes animales de la granja, suministrándose generalmente mezclado con agua en forma de amasijos o berbajos. A esos amasijos destinados a los pavos se podían incorporar otros elementos como pan duro remojado y sobre todo, ortigas picadas (Urtica urens). Sobre las ortigas, RABAL SAURA, G.: 2014, p. 62, recogió en Perín, zona a la que se refiere este trabajo, que son consideradas como un buen alimento para las aves de corral por aumentar la puesta de huevos; así mismo, el citado autor en otro de sus trabajos apunta que las ortigas amasadas con harina les encantan a los pavos pequeños (RABAL SAURA, G.: Hablando de pájaros (ornitología popular murciana), Murcia: Autor, 2017, p. 241). LARBALÉTRIER, A. y VERMONT, A.: ca. 1900 , p. 281, también citan la utilidad de las ortigas machacadas como primer alimento fortificante para los pavipollos, junto a otros ingredientes como leche cuajada, miga de pan, salvado, huevos duros o vino. N. del A.: La ortiga presenta sobre su superficie unos pelos urticantes capaces de provocar irritación y picor intenso, por lo que el hecho de picarlas o machacarlas debe destruir esas estructuras y, por ende, su efecto pernicioso.

11 Vinagrillo (Oxalis pes-capprae), serrajas y serrajones (Sonchus sp.), etc. Sobre el género Sonchus, llama la atención lo recogido por RABAL SAURA, G: «Cuando la chicoria echa flor. Etnobotánica en Torre Pacheco», Revista Murciana de Antropología, 6, (1999)-2000, p. 98, donde señala como vernáculo la voz cerrajón pavero, lo cual indica de forma inequívoca que eran plantas habitualmente consumidas por la especie animal que nos ocupa. Por otro lado, y aunque considerada como una mala hierba, que no formaba parte habitual de su dieta, también citaré a las plantas del género Amaranthus, ya que debido a la disposición cónica de sus flores se la conoce popularmente como moco de pavo (Ibídem, p. 78).

12 LARBALÉTRIER, A. y VERMONT, A.: ca. 1900, pp. 282-3, también indican que se les lleva a pastar al campo, donde hacen la caza de la langosta y otros insectos. Resulta curioso otros alimentos que aprovechan en la campiña francesa, lugar de origen de los autores, como son los hayucos (frutos del haya), las castañas o las bellotas, curiosamente frutos también consumidos por el ganado porcino en montanera. Igualmente, no queda duda de su carácter omnívoro cuando leemos que, tras la caída del sol y su vuelta a la granja, se les daba, además de variados alimentos de origen vegetal, desperdicios de carne y lombrices. 
Cuando se acercaba la Pascua, época del sacrificio, era habitual enriquecer la dieta, suplementando la ración diaria ${ }^{13}$ con amasijos o embuchándoles habas remojadas «pa que engordaran más, les abrías el pico y se las dabas». Otro curioso método, que pretendía facilitar el engorde de los animales, consistía en arrancar las plumas en crecimiento de las alas y, fundamentalmente, de la cola. ${ }^{14}$ Estas plumas, conocidas como chupones, eran fácilmente reconocibles por tener un cañón más grueso y ricamente irrigado.

\subsection{Sistema de explotación y de alojamiento}

El régimen de producción en el que se mantenían era de tipo semi-extensivo, ${ }^{15}$ campeando durante el día, cuando no había sembrados ni higos chumbos, junto a las gallinas y pollos por bancales, palares, lejíos y mulares. ${ }^{16} \mathrm{Al}$ oscurecer se guarecían en un gallinero, generalmente de morfología cúbica, paredes de piedra seca y techumbre plana de colañas, cañizo y láguena (launa), teniendo como único elemento interior un simple tronco colocado a cierta altura y que hacía de aseladero (el palo del gallinero). En las temporadas en las que no podían campear, deambulaban durante el día por algún patio tapiado o por algún cercado (tradicionalmente fabricado con cañas -Arundo donax-). El alimento en grano no se les ofrecía en un comedero, sino que se les esturreaba por el suelo varias veces al día y en diferente cuantía, en función de si salían o no a pastar. Sí que disponían de un bebedero, formado por un bloque de piedra con una concavidad esculpida (pilón de piedra), y de un no menos rudimentario comedero, conocido como gamella,

13 LARBALÉTRIER, A. y VERMONT, A.: ca. 1900, pp. 285-6, indican que «la ceba (DRAE: alimentación abundante y esmerada que se da al ganado para que engorde) comenzará al fin del otoño o principio del invierno [...], se les dará una ración suplementaria» e incluso hablan de embucharles bolas de masa.

14 RABAL SAURA, G.: 2017, p. 254, también recoge esta práctica, pero la circunscribe a realizarla en las plumas de la cola y durante la luna creciente. Con este método los cuidadores debían entender que si la sangre no se desviaba a las plumas, facilitaría el engorde del animal; no obstante, quizás de una forma empírica sí que se conseguía algún beneficio, ya que un animal con sus plumas mermadas sería más difícil que intentara volar (cosa frecuente en los pavos) o que gastara energía en los rituales de cortejo y lucha (para los que necesita exhibir la plenitud de su plumaje).

15 LARBALÉTRIER, A. y VERMONT, A.: ca. 1900, pp. 276 y 284, inciden en la imperiosa necesidad de que los pavos que ya tienen cierto desarrollo, el cual se puede mensurar como adecuado si ya han empezado a desarrollar las características carúnculas que adornan su cabeza y cuello (con dos o tres meses de edad), deben salir a pastar; de lo contrario, enflaquecen en lugar de engordar, e indican que la época de campeo coincide con el verano y el principio del otoño.

16 VAN TRICHT, P. VICTOR: 1902, p. 6, describe tal situación de este modo tan expresivo: «Al gallo y las gallinas vienen a mezclarse pomposos y ridículos los pavos y sus consortes [...]». Palar: terreno poblado de chumberas. Lejío: ejido. Mular: estercolero. 
fabricado con la base de un arzabarón (influorescencia de Agave americana) vaciado del material acorchado de su interior, y donde se depositaban los amasijos.

Las contadas familias que poseían manada de pavos delegaban en los niños de la casa la responsabilidad de su cuidado. ${ }^{17}$ Para ello, auxiliados con una caña y llamándolos con la voz «pai, pai, pai», «pau, pau, pau» o «pavi, pavi, pavi» ${ }^{18}$ conseguían manejarlos y guiarlos por los bancales, en una tarea conocida como guardar los pavos.

Como ya se ha indicado, se recogían al anochecer para protegerlos del ataque de las alimañas, como la temida zorra o la garduña. Si por alguna circunstancia se producía una demora en tal hábito, tenían cadencia por encaramarse a alguna altura, generalmente a un árbol o a una lera (tapia) donde buscar refugio para pasar la noche. Me decían que «donde les pillaba se subían» ${ }^{19}$ o que hay que «recoger los pavos antes que oscurezca, que como se suban por ahí, por los almendros, ya no hay quien los baje; a uno le dio por dormir en las palas y la sorra se lo comió»». Si la raposa era el principal depredador nocturno, durante el día había que estar vigilante de cuervos y gavilanes, ${ }^{20}$ aves que habitualmente merodeaban por las inmediaciones de las casas de labor con la intención de cazar a los ejemplares de corta edad de la avifauna doméstica.

17 Ejemplos de familias locales con manada de pavos fueron la de la tía María la Apañá y la de Perico Joaquín. LARBALÉTRIER, A. y VERMONT, A.: ca. 1900, p. 282, apuntan la misma costumbre, indicando que «un niño pequeño puede conducir al pasto una gran cantidad de pavos sin gran trabajo: basta con una vara para indicarles la dirección que deben tomar [...]».

18 RUÍZ MARÍN, D.: Vocabulario de las hablas murcianas, Murcia: Diego Marín, 2017, 492, recoge la voz pavipavi para llamar a los pavos pequeños y birrubirru para los grandes. Las otras dos aquí aportadas no aparecen en ninguno de diccionarios dialectales murcianos.

19 VAN TRICHT, P. Víctor: 1902, p. 59, indica que tal comportamiento es motivado por una reminiscencia etológica de sus ancestros salvajes, lo cual les permitía «librarse del lince, el más terrible de sus enemigos después del hombre».

20 Cuervos y gavilanes, abundantes en épocas pasadas, suponían una amenaza para los pollos de corta edad. Cuentan que cuando se veían sobrevolar por el entorno de las casas, había que recoger rápidamente a las lluecas (gallinas o pavas en época de cría) para que no se llevaran los pollicos. La voz de alarma para ahuyentar al depredador y avisar a las vecinas era una señal establecida que consistía en vocear «uuuuuh» de forma repetida. A este respecto he de citar, por su similitud, lo aportado por RABAL SAURA, G.: 2017, p. 100, y es que apunta, para diferentes localidades de la región de Murcia, que cuando las mujeres descubrían el vuelo de algún cuervo, los espantaban gritándoles «ru, ru, ru». Para que los pollitos no se alejaran de las madres, y éstas a su vez no se alejaran de zonas concretas donde podían ser supervisadas de cerca por las mujeres de la casa, las lluecas se amarraban con una cuerda de filete de un par de metros, por medio de una lazada corrediza desde una de las patas al tronco de algún árbol o de un palón. Otros métodos de protección, cuando eran recién nacidos, consistían en cubrirlos con una pollera de esparto (cúpula de esparto trenzado, similar a las sarrias, de unos $80 \mathrm{~cm}$ de diámetro y otros tantos de alto, bajo la que se encerraban llueca y pollitos -o pavitos-). Tan frecuentes eran estos ataques a la avifauna doméstica, que surgieron expresiones jocosas y fijas como «Pedro, Pedro, / saca la escopeta / y mata al cuervo» o «Juan, Juan, / saca la escopeta / y mata el gavilán», las cuales aún persisten, aunque ya fuera de contexto. 


\subsection{Etnoveterinaria}

Los informantes coinciden en afirmar que antes las aves de corral no se ponían malas nunca, y que es ahora cuando «hay muchas plagas». No obstante, he podido documentar algunos datos interesantes o al menos curiosos. Así, existía la costumbre de añadir al agua de bebida de estos animales un poco de «azulete del que se le echaba a la ropa [...] pa'si cogían caguetilla o moquillo». ${ }^{21}$ Posiblemente buscando un efecto similar también me contaban que se ponían, dentro del agua y pillados con una piedra, tallos de una planta conocida como rabogato (Sideritis $s p$.). ${ }^{22}$ También, para combatir las plagas de piojos que les afectaban, conocidos popularmente como caparrilla, se acostumbraba a colgar dentro de los gallineros tallos de ruda (Ruta angustifolia).

No menos sorprendente es el procedimiento utilizado cuando ingerían algún invertebrado considerado pernicioso, señalando como ejemplo explícito «los ciempiés o cualquier bicho así». Indicaban que los animales «se ponían muy malos, pa morirse», y que entonces se les abría el buche, se vaciaba su contenido y se les cosía con aguja e hilo de coser. ${ }^{23}$

Para concluir, apuntar que cuando los machos alcanzan la madurez sexual son frecuentes las peleas ${ }^{24}$ entre ellos, produciéndose múltiples heridas que se tra-

21 El azulete era un polvo de color añil usado como blanqueador óptico de la ropa. Tradicionalmente se extrajo de la maceración de ciertas plantas que contenían este pigmento. RUÍZ MARÍN, D.: 2007, pp. 128 y 438, equipara la caguetilla y el moquillo con síntomas de tipo diarreico y catarral respectivamente. N. del A.: Ambos síntomas son del todo inespecíficos y, por tanto, comunes a múltiples enfermedades; no obstante, es frecuente que la caguetilla esté provocada por coccidios o enterobacterias, mientras que el moquillo se puede relacionar con el coriza aviar.

22 RABAL SAURA, G.: 2014, p. 206, recoge la misma práctica, pero con ramas de taray (Tamarix sp.) y para prevenir el moquillo.

23 Los ciempiés son animales potencialmente venenosos, para lo cual es necesario que inoculen el veneno con sus apéndices bucales. Su característica coloración corporal, que podemos considerar como de alarma, con tonos amarillentos, anaranjados y negros sirve para poner en alerta a otros animales para que no se les moleste. Dicho esto, y aunque al pavo se les tacha de animal necio, parece poco probable que intente comerse uno, pero si lo hiciera, y el miriápodo ya pereció por un contundente picotazo y por ende ya no puede picar, no debiera darle mayor problema. Por tanto, la temeraria intervención practicada, conocida a nivel veterinario como ingluviotomía, no parece tener mucho sentido. Aunque dicen que los animales intervenidos se recuperaban sin mayor problema, llevar a cabo esa técnica quirúrgica, sin anestesia, sin asepsia y con sutura capilar, en mi opinión, no debió estar exenta de problemas, existiendo un alto de riesgo de infección y de dehiscencia de la sutura.

24 LARBALÉTRIER, A. y VERMONT, A.: ca. 1900, p. 276, apuntan que «la hembra es apacible e inofensiva, en cambio el pavo [...] es pendenciero y malo, ataca sin razón a las gallinas, gallos, patos y los perros [...]. Llega su maldad hasta el punto de atacar a los niños [...]. Su cólera es tan violenta que es proverbial $[\ldots] »$. 
taban con aceite y ceniza. Me contaban que «se encarnisaban, se ponían fieras, se estrosaban las cabesas dándose picotasos, se ponían enferrusíos, y no soltaban, aunque estuvieras con la escoba dándoles o les tiraras un cubo de agua».

\subsection{Final del ciclo}

La cría y engorde tradicional se prolongaba durante 7 u 8 meses: desde el momento de la eclosión en primavera, hasta su sacrificio en las fechas próximas a la Navidad (días 23 o 24 de diciembre). Y es que como me contaban, «a los pavos, cuando les corría mala cabañuela ha sio pa la Pascua». ${ }^{25}$ Ya lo dice el refranero: «el pavo, por Navidad; y el conejo, por San Juan».

Puesto que sólo se solía matar uno o dos animales, si se engordaban varios, el resto eran vendidos a los recoveros, ${ }^{26}$ lo que suponía un acicate para las misérrimas economías familiares de la zona. En ocasiones, si la necesidad lo obligaba, o según gustos culinarios particulares de cada casa, se criaban en exclusividad para comerciar con ellos. En esos casos, la carne de una gallina o de un pollo suplía al pavo en el tradicional caldo con pelotas del primer día de Pascua (25 de diciembre). Y es que como me explicaban, otrora, sólo se comía carne en Navidad (o en alguna fecha señalada del verano como la Virgen de Agosto).

\section{LA MATANZA DEL PAVO ${ }^{27}$}

«La víspera de Nochebuena o hasta el día de Nochebuena por la mañana», habiendo alcanzado un peso de unos 6 u $8 \mathrm{~kg}$ los machos y de unos 4 o 5 las hem-

25 Las cabañuelas son un método popular para predecir el tiempo atmosférico a un año vista; por tanto, la expresión «mala cabañuela» pronostica un mal augurio, en este caso al pavo durante la Pascua (la Navidad), ya que por esas fechas ha alcanzado un peso óptimo para su sacrificio y es cuando tradicionalmente se consumía.

26 Recoveros del lugar fueron Juan Regino, Perico de los Morenos, el Torres o Castejón. Comerciaban fundamentalmente con aves de corral, huevos, palomas, conejos y chotos, actuando de intermediarios. Los compraban a las mujeres, yendo de casa en casa, a cambio de dinero o de otras mercancías como enseres domésticos, telas o incluso comida. Posteriormente ellos los vendían en el mercado de Cartagena.

27 Aunque no lo he podido constatar en la zona de estudio, quiero señalar lo aportado por GARCÍA HERRERO, G., SÁNCHEZ FERRA, A.J. y JORDÁN MONTES, J.F.: «La memoria de Caprés», Revista Murciana de Antropología, 4, 1997, pp. 121 y 138: apuntan que en Caprés (Fortuna), durante la Navidad del primer año de luto, no se mataba pavo (ni cerdo), ni se consumían sus platos típicos, realizando tal actividad a posteriori, fuera del periodo festivo. 
bras, los animales eran sacrificados. Se tenía predilección por la carne de pava, descrita como «más gustosa, más fina», tachando la del pavo como «más desavoría». ${ }^{28}$ No suponía una fiesta equiparable a la matanza del cerdo (o la marraná del chino, que es como se le denomina en la zona de estudio), pero sí que tenía su particular parafernalia. Puesto que era el ingrediente principal para las comidas de la época navideña, y ésta es una fiesta familiar, la muerte y preparación de su carne sólo incluía a los miembros de la casa, no acudiendo vecinos, ni amigos y obviamente no ofertando presentes, como sí que se hacía con el cerdo. Tampoco era preciso la presencia de un matarife profesional que matara y descuartizara al animal, labor imprescindible cuando se trataba de un cerdo, bastando la pericia de alguien de la casa, o como mucho de algún conocido.

\subsection{Modo de sacrificio tradicional}

Sujetado por una o dos personas, se subía sobre un poyo, mientras que otra cogía el pico, forzando una ventroflexión que lo situaba en paralelo al cuello. A continuación, se realizaba un corte transversal en el pescuezo, a la altura de la articulación atlanto-occipital, provocando el desangrado y muerte del animal al seccionar el seno venoso occipital. ${ }^{29}$ La sangre se recogía en un lebrillo, se dejaba que cuajara y se le realizaban varias cruces con la punta del cuchillo usado en el sacrificio.

28 LARBALÉTRIER, A. y VERMONT, A.: ca. 1900, p. 288, hablan de pesos algo mayores (10 los machos y 6 las hembras), seguramente fruto de una alimentación más rica y abundante; no obstante, son coincidentes en señalar que la carne de pava es mucho más sabrosa.

29 Este inusual método, ya que en otras especies se realiza un degüello o punción de los grandes vasos sanguíneos por la parte lateral y/o delantera, quizá se implementó para evitar contaminar la recogida de la sangre con posibles contenidos que, procedentes del buche, pudieran salir a través de la herida en el caso de realizar un abordaje habitual. Subrayar también el profundo conocimiento empírico que tenían sobre anatomía aviar, ya que el citado seno venoso occipital es una estructura anatómica poco conocida y estudiada a nivel científico, pero que, a los lugareños, fruto de la experiencia, les sirvió para realizar un sacrificio adecuado y efectivo. No obstante, la falta de pericia en el manejo del cuchillo y en el conocimiento anatómico, podían provocar situaciones tan rocambolescas como la que vivió una de las informantes, la cual contaba cómo un pavo agonizante escapó de las manos inexpertas de los adolescentes de la casa que se estaban iniciando en tales prácticas y deambuló una decena de metros con la cabeza colgando. Por tanto, queda patente que no es cuestión de cortar alegremente en profundidad, sino cortar lo justo y en el sitio preciso. 


\subsection{Gastronomía típica}

Esa sangre se consumía frita con cebolla y/o se usaba en la elaboración de las típicas pelotas o albóndigas. ${ }^{30} \mathrm{Y}$ es que el plato estrella del campo de Cartagena elaborado con pavo era el cocido con pelotas del primer día de Pascua. Con el resto de la carne, que había que consumir en pocos días porque no había medios de refrigeración, se realizaban guisos con patatas, fritangas con patatas o con tomate y pimiento, ${ }^{31}$ asada a la plancha o en $\operatorname{arroz}^{32}$ (con la carne de la pechuga o de los contramuslos hecha taquitos).

Se aprovechaban también sus vísceras. ${ }^{33}$ Así, las tripas se abrían con tijera, se lavaban, se ponían en sal y vinagre, con trozos de limón, se enjuagaban y se liaban sobre la parte sin plumas de las patas (región tarso-metatarsiana), las cuales previamente habían sido chuscarradas, rascadas y desprovistas de uñas, escamas y suciedad. Esto se añadía al guiso de carne de pavo y patatas, y era considerado una delicatessen. También se consumían en los guisos el hígado (teniendo la precaución de retirarle la hiel -la vesícula biliar-), la moleja (que se abría por su eje largo, se vaciaba de contenido y se le desprendía la correosa capa de la mucosa) y hasta la madre (-el oviducto- previamente limpiada con sal).

\section{EL PAVO EN EL FOLCLORE Y EN EL HABLA POPULAR}

\subsection{Costumbres y relatos populares}

Era habitual durante el otoño, momento en el que los animales ya han desarrollado en su totalidad los caracteres sexuales que diferencian a machos de hembras, dirigirse al pavo (al macho) barruntándole su inevitable destino: «Pavooo, ¡la Pascua viene!», a lo que el animal respondía con su conocido «ijaló, jaló,

30 También conocidas como relleno, eran elaboradas con la carne picada de la pechuga del pavo, junto a magra de cerdo o a pierna de cordero, algo de sangre del pavo (opcional), longaniza blanca, embutido blanco, butifarra (opcional), piñones, ajo, perejil, molla de pan y huevo. Hasta hace no muchas décadas, no había picadoras de carne, por lo que tal actividad la realizaban las mujeres de la casa de forma manual ayudadas de un cuchillo y/o un hacha bien afilados.

31 GARCÍA HERRERO, G., SÁNCHEZ FERRA, A.J. y JORDÁN MONTES, J.F.: 1997, pp. 149 y 211, indican para la aldea de Caprés (Fortuna) que era el plato típico para consumir durante el día de Año Nuevo, señalando que, aunque se mataba en Nochebuena, no se consumía hasta ese día.

32 Como curiosidad indicar que esta elaboración es tradicional de la gastronomía lorquina.

33 También se hacía con las del pollo. 
jaló!». ${ }^{34}$ Referente a esto, decir que en la zona de estudio he recogido un breve cuento popular, considerado un mimologismo y catalogado como ATU $236^{*}, 35$ donde se interpreta que esas vocalizaciones dichas por el pavo, traducidas al lenguaje humano, quieren decir «déjalo, déjalo, déjalo». Es decir, se asume que el pavo sabe lo que le espera y responde insinuando que nos olvidemos del tema. Esta práctica suponía un cierto divertimento entre la chiquillería, aunque hay que decir que, tras dirigirse al pavo cinco o seis veces en tales términos, el animal dejaba de responder.

Me contaban también una anécdota, que bien podría encuadrarse dentro de los cuentos de tontos. ${ }^{36}$ En ella, una mujer descubre una tijereta en el logar (hogar) y llama al marido para que traiga al pavo grande y se la coma.

\subsubsection{Fraseología}

El repertorio fraseológico donde el pavo es protagonista es amplio y, como veremos, hace referencia a sus características físicas o comportamentales, correlacionándolas con caracteres humanos. Así, se dice que algo «no es moco de pavo» cuando algo es de importancia o no es un tema baladí. Otra expresión es «hacer la rueda», modo con el que se conoce el ritual de cortejo del pavo, y que tiene el sentido de agasajar a alguien de forma desmesurada (hacer la pelota). «Subírsele a uno el pavo» es equivalente a pavonearse, y hace referencia a tenérselo muy creído, como el pavo macho cuando corteja. ${ }^{37}$ Estás en «la edad del

34 Como ya se ha indicado, el macho es de mayor tamaño que la hembra. Ambos muestran la piel de la zona de cabeza y cuello desnuda de plumas (apterios) y provista de unos sobrecrecimientos carnosos llamados carúnculas, que son mucho más aparentes en los machos que en las hembras. La carúncula situada sobre el pico es extensiva, de forma cónica y se la conoce como moco, llegando a medir en los machos ocho o diez centímetros. Todas estas carnosidades toman coloraciones en tonos rojos, blancos y azules que varían según el estado del animal. El macho exhibe una gran cola que despliega a modo de abanico durante el cortejo al tiempo que ahueca el plumaje, deja caer las alas hasta que casi rozan el suelo, da vueltas en círculo y realiza ciertos resoplidos o vocalizaciones características, conociéndose este comportamiento como hacer la rueda.

35 Cfr. RABAL SAURA, G.: 2017, pp. 255-7, donde se recogen varios relatos más, en diferentes puntos de la geografía regional, en los que igualmente se humanizan y se intentan explicar las vocalizaciones dichas por los pavos.

36 Como se puede observar, la escena descrita es del todo surrealista, siendo absurdo meter al animal en casa con la intención de que cazara, o aprovechara como alimento, un único insecto que apenas llega a los dos centímetros de largo. No obstante, en ella queda patente la consabida gran avidez que los pavos muestran por alimentarse de bichos.

37 CUVIER, G.: Lecciones elementales de la historia natural de los animales, Valencia: Imprenta Cabrerizo, 1834, p. 234, lo define a la perfección indicando que «el pavo es emblema de la ignorancia orgullosa». 
pavo», cuando entras en la adolescencia, momento en el que el pavo comienza a expresar sus típicos comportamientos de pavoneo, ${ }^{38}$ cortejo y peleas. «Eres un pavo», si muestras un comportamiento atontolinado o eres un engreído. «Eres una pava en huevos», si eres una mujer boba o insulsa. "Comes a lo pavo», si comes mucho y rápido. Te «embuchan como a un pavo», cuando debes tragar sin masticar, como cuando se embuchan a las pavas cluecas o a los pavos de engorde al final del ciclo. «Estás empavonao o colorao como un pavo», cuando por motivos varios presentas una cara extremadamente sonrojada. Se dice que «están pelando la pava», cuando dos enamorados pasan gran cantidad de tiempo charlando, ya que el desplumado manual tradicional es una tarea laboriosa que conlleva bastante tiempo. Si espetas «pa los pavos», estás dando una negativa. «Meter los pavos a la sombra», sería equiparable a la expresión cantar las cuarenta e indica que queremos intimidar o dar una lección a alguien. Cuando hace mal tiempo y estás mal de ánimo, se apostilla con la expresión «estoy atontao como los pavos»; esto es por-

\begin{tabular}{|lll|}
\hline \multicolumn{1}{|c|}{ FRASE } & IDEA O TEMA RELACIONADO \\
\hline 1 & No es moco de pavo & Importancia \\
2 & Hacer la rueda & Agasajar desmesuradamente \\
3 & Subírsele el pavo & Envanecerse \\
4 & La edad del pavo & Adolescencia \\
5 & Ser un pavo & Tonto \\
6 & Ser una pava en huevos & Insulsa \\
7 & Comer a lo pavo & Glotonería \\
8 & Embuchar como a un pavo & Ingesta rápida \\
9 & Estar colorao como un pavo o empavonao & Cara roja \\
10 & Estar pelando la pava & Negativa \\
11 & Pa los pavos & Intimidar \\
12 & Meter los pavos a la sombra & Astenia ambiental \\
13 & Estar atontado como los pavos & Insulto \\
14 & Que te den un tiro de mierda pavo & Crítica (preocupaciones reales) \\
15 & Te hacía falta una manaíca de pavos & Asunto concluido \\
16 & Tener el pavo pelao & Interjección de disgusto \\
17 & ¡Adiós mis pavos! & \\
\hline
\end{tabular}

Figura 1. Repertorio fraseológico y sus correspondencias ideológicas o temáticas.

38 LARBALÉTRIER, A. y VERMONT, A.: ca. 1900, p. 272, los tacha de majaderos y de tener una marcha tontamente solemne y un cloqueo insípido, señalando que la tontería está menos caracterizada en la hembra que en el macho. Una entrevistada lo contaba así: «los pavos son muy tontos, nacen tontos y mueren tontos; como tomen pa'llá...lo mismo los grandes que los chicos». 
que los pavitos son muy sensibles a las bajas temperaturas, ${ }^{39}$ y se dice que el tiempo de levante los atonta. Si te dicen «anda y que te den un tiro de mierda pavo», te están mandando a hacer morcillas, mientras que si te dicen que «te hacía falta una manaíca de pavos», están insinuando que te vendría bien tener una ocupación en lugar de estar preocupándote de nimiedades o de asuntos que nada te incumben.

Para terminar este apartado quiero citar dos expresiones más, recogidas por A. Sánchez Verdú Y F. Martínez Torres, en su monumental obra sobre el habla de Cartagena y que tienen al pavo como protagonista: «tener el pavo pelao: dicho que se emplea para referir que un asunto está concluido» y «jadiós mis pavos!: exclamación utilizada ante una situación catastrófica o incontrolable». ${ }^{40}$

\title{
4.3. Dichos, canciones y juegos
}

Hay un dicho que cuenta, a modo de diálogo entre el pavo y la pava, sus habituales destinos: «Vísperas de Nochebuena le dice el pavo a la pava: / -Tú te quedarás criando, que a mí me matan mañana». ${ }^{41}$

También tenemos dos variantes de una coplilla que, de modo jocoso, deja patente que tras la muerte del pavo no se llevaban presentes a los vecinos, cosa que sí se hacía tras la matanza del cerdo. Además, evidencia la situación que se genera durante el desplume manual del animal. Éste se realizaba en los alrededores de las casas, colgando al animal de una pata a la rama de un árbol y situándose a su alrededor una o más personas que le iban retirando las plumas por tracción. Si hacía viento, estas plumas eran vehiculadas a cierta distancia, pudiendo acabar en las propiedades colindantes, y de ahí la copla:

\author{
Ha llegado Navidad \\ y vamos a matar el pavo. \\ Las plumas se las daremos \\ al vecino más cercano.
}

39 Tanto es así, que una informante, abuela del que esto suscribe, contaba la anécdota que le aconteció un año en el que la pava le sacó una pollada de pavicos en el mes de febrero. Con las bajas temperaturas propias de esa época, los animales aparentemente fallecieron y ella procedió a arrojarlos al tejado para que los gatos dieran cuenta de ellos, pero cuál fue su sorpresa cuando, con el sol de mediodía, su sorprendido marido la avisó de que había pavicos piulando en el terrado. LARBALÉTRIER, A. y VERMONT, A.: ca. 1900, pp. 277, 280-2 y 289, también se hacen eco de lo sensibles que son a las bajas temperaturas y a la humedad durante los primeros meses de su desarro1lo, haciendo un especial hincapié, por ser especialmente vulnerables, al momento en el que les aparecen las carúnculas de la cabeza en torno a los dos o tres meses.

40 Gran diccionario popular de Cartagena y su comarca, Cartagena: La Opinión, 2002, pp. 417-18.

41 RABAL SAURA, G.: 2017, pp. 256, recoge un diálogo similar en Gebas (Alhama de Murcia) que dice así: «Válgame, qué pocas Navidades contaron mis abuelos. No se hacían viejos». 


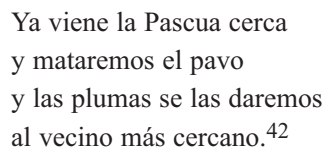

Citaré otra copla, en este caso de las consideradas como canciones de faena, que eran las cantadas durante la realización de las tareas del campo, que dice así: «Las mujeres pa misa van platicando, / tengo una pava en huevos y otra sacando».

Para finalizar este apartado nombraré un juego de corro $^{43}$ que servía de divertimento a las niñas y donde se intentaba resaltar el carácter atontolinado de estos animales, extrapolándolo a los humanos. Se requería un número impar de participantes que, agarradas de la mano y haciendo un corro, iban cantando la canción «al pavo, pavito, pavo, que pavito ya está aquí», momento en el que paraban y se juntaban por parejas. A la niña que se quedaba sola se le gritaba «ipavo, pavo, pavo!», y vuelta a empezar.

\subsection{Otros usos del pavo}

Los más pequeños de la familia, tras la muerte del pavo, aprovechaban el buche para, una vez vacío y limpio, insuflarle aire e hincharlo como un globo, ${ }^{44}$ jugar con él, y «cuando se explotaba, pos s'a explotao». Se conseguía un globo o balón de más de un palmo de diámetro que incluso botaba. Decir que el buche del pavo es sacciforme (con forma de saco) y de grandes dimensiones, lo cual facilitaba tal práctica.

Igualmente, las largas y fuertes plumas de las alas y la cola (rémiges primarias y rectrices) las usaban para confeccionar carros con los que jugar. ${ }^{45}$ Éstos se fabricaban clavando las plumas en la periferia de un tallo de pala (chumbera, Opuntia maxima), «por to alrededor se le ponían las plumicas y era pos la barandilla del carro»; de ese modo se simulaban las estacas y varales que conforman la típica caja de un carro tirado por bestias. Cortando otra pala y dándole forma circular, se le podían adicionar detalles como las ruedas, y perforando el extremo

42 La informadora señala que es la letra de una jota.

43 Cfr. otra versión más elaborada en BARRENO MORENO, A., et al.: Chuperete merenguete, Cartagena: ed. Corbalán, 2004, pp. 118-9.

44 En el siguiente enlace se puede ver un vídeo donde se explica el modo se confeccionar estos globos: $<$ https://www.youtube.com/watch?v=dbxBbbG_ovk>.

45 CARMONA MARTOS, J. M.: 2015, p. 244, apunta una práctica similar, aunque en este caso usando sólo pencas de chumbera y palitos. 
acuminado de la pala se practicaba un agujero donde amarrar un cordel del que tirar y arrastrar el carro una vez terminado.

Las plumas de las alas también eran usadas, pero en este caso sólo por las niñas, para aprender a tricotar. Así, madres o abuelas elaboraban sencillas agujas con las que iniciar a las pequeñas en la práctica de hacer punto (hacer molde, tricotar o tejer) e incluso en la de hacer ganchillo. El proceso consistía en retirar las barbas de la pluma por tracción, dejando sólo las situadas en la parte final del raquis, siendo obviamente, el cálamo o cañón el extremo de la simulada aguja.

También he registrado en la zona el uso de las plumas que recubren el cuerpo del animal como material de relleno para cojines.

Señalar que en otros lugares de nuestro entorno cercano también está documentado el uso de las plumas del pavo, pero en este caso para escribir con tinta. ${ }^{46}$ Todos estos ejemplos nos muestran cómo en épocas de carestía se agudizaba el ingenio, aprovechando los restos del animal para fines variopintos.

Concluyo refiriéndome a la ya citada costumbre de los pavos de encaramarse a los árboles y la interpretación que de esto se hacía. Y es que cuando tal comportamiento lo hacían durante el día (ya que en el ocaso lo hacen para guarecerse y dormir) era tomado, al igual que la presencia de hormigas con alas o de caracoles en las cruces de los árboles, como un barrunto de agua, es decir, como un método de predicción en lo que podemos llamar la meteorología popular.

\section{CONCLUSIONES}

Visto lo visto, a la mayor de las gallináceas domésticas, al pavo, bien podríamos tacharlo de «cerdo emplumado». Y es que si del porcino se dice que de ellos se aprovechaba todo y se los equiparaba, metafóricamente, con una hucha, el pavo no se queda atrás. ${ }^{47} \mathrm{Ha}$ quedado patente cómo se utilizaba la práctica totalidad de su cuerpo, cómo está presente de forma muy destacada en el folklore, las costumbres y la fraseología local, y cómo su engorde y posterior venta supuso una fuente de ingresos adicional en las familias de la zona. Igualmente señalar cómo su alimentación, basada en lo que aportaba el entorno, su alojamiento en simples gallineros de piedra y su sistema de explotación, en modalidad semiextensiva, son indicativos de que era una especie totalmente adaptada e integrada al medio rural estudiado. También es destacable la estacionalidad en su sacrificio con objeto de elaborar el plato estrella de la gastronomía del lugar: las pelotas del cocido del día de Navidad.

46 CARMONA MARTOS, J. M.: 2015, p. 254. Además, LARBALÉTRIER, A. y VERMONT, A.: ca. 1900 , p. 288 , citan el uso en Francia de las plumas de las alas y de la cola para hacer plumeros.

47 ORTEGA MADRID, J.: 2017, pp. 249-270. 


\begin{tabular}{|ll|}
\hline \multicolumn{1}{|c|}{ SIMILITUDES } & \multicolumn{1}{c|}{ DIFERENCIAS } \\
\hline Alimentación omnívora & Habitual uso del vino como reconstituyente \\
Explotación semi-extensiva & No se requiere de un materife especializado \\
Sacrificio estacional & No hay fiesta de la matanza \\
Aprovechamiento integro de su cuerpo & No está presente en la medicina popular \\
Fuente de ingresos familiar por su venta & Uniformidad de los alojamientos ganaderos \\
Generalmente engorde sin reproducción & Trabajo exclusivo de mujeres (y niños) \\
Generalmente engorde de 1 o 2 ejemplares & No se castran \\
Abundante presencia fraseológica & Escasa presencia en los relatos populares \\
\hline
\end{tabular}

Figura 2. Comparativa etnográfica, a nivel local, con el cerdo.

Quiero poner de relieve también que la mayoría del trabajo relacionado con esta especie era llevado a cabo por las abnegadas mujeres de nuestros campos, hecho que no pasaba con otros animales, como era el caso del ganado caprino, el de cerda o las bestias de carga, donde el hombre sí que participaba de una forma más activa e incluso de una forma casi exclusiva.

\section{BIBLIOGRAFÍA}

Barreno Moreno, A., et al.: Chuperete merenguete, Cartagena: ed. Corbalán, 2004.

Carmona Martos, J. M.: Almería tierra de cortijos, 2a edición, Almería: Autor, 2015.

CUVIER, G.: Lecciones elementales de la historia natural de los animales, Valencia: Imprenta Cabrerizo, 1834.

Larbalétrier, A. y Vermont, A.: Los animales de corral, París: Garnier Hermanos, ca. 1900.

García Herrero, G., SÁnchez Ferra, A. J. \& Jordán Montes, J. F.: «La memoria de Caprés», Revista Murciana de Antropología, 4, 1997.

Gómez ORTín, F.: Vocabulario del noroeste murciano, Murcia: Editora Regional de Murcia, 1991.

Ortega Madrid, J.: «Pocilgas tradicionales en la diputación de Perín», IV Congreso Nacional de Etnografía del Campo de Cartagena, Cartagena: UPCT, 2015, pp. 96-107.

Ortega Madrid, J.: «Etnografía asociada al porcino en el entorno de Perín (Cartagena)», Revista Murciana de Antropología, 24, 2017, pp. 249-270.

RABAL SAURA, G: «Cuando la chicoria echa flor. Etnobotánica en Torre Pacheco», Revista Murciana de Antropología, núm. 6, (1999)-2000. 
Rabal SAURA, G.: El saber botánico popular en el municipio de Cartagena, Cartagena: UPCT, 2014.

Rabal SAura, G.: Hablando de pájaros (ornitología popular murciana), Murcia: Autor, 2017.

Ruíz MARín, D.: Vocabulario de las hablas murcianas, Murcia: Diego Marín, 2017.

SÁnchez ConesA, J. «La gastronomía navideña», La Verdad, 18 de diciembre de 2013, p. 6.

SÁnchez Verdú, A. y Martínez Torres, F.: Diccionario popular de nuestra tierra, Murcia: La Opinión, 1999.

SÁnchez Verdú, A. y Martínez Torres, F.: Gran diccionario popular de Cartagena y su comarca, Cartagena: La Opinión, 2002.

VAN TRICHT, P. V.: Nuestros animales domésticos (IV las aves del corral), Bilbao: Imprenta del Corazón de Jesús, 1902. 